Pesq. Vet. Bras. 36(Supl.1):21-32, junho 2016 DOI: 10.1590/S0100-736X201600130004

\title{
Estudo comparativo da diferenciação osteogênica das células tronco mesenquimais da medula óssea e do tecido adiposo de cães adultos ${ }^{1}$
}

\author{
Endrigo G.L. Alves²*, Rogéria Serakides ${ }^{2}$, Jankerle N. Boeloni ${ }^{3}$, Isabel R. Rosado ${ }^{2}$, \\ Natalia M. Ocarino ${ }^{2}$, Humberto P. Oliveira² ${ }^{2}$, Alfredo M. Góes ${ }^{4}$ e Cleuza M.F. Rezende ${ }^{2}$
}

\begin{abstract}
Alves E.G.L., Serakides R., Boeloni J.N., Rosado I.R., Ocarino N.M., Oliveira H.P., Góes A.M. \& Rezende C.M.F. 2016. [Comparative study of the osteogenic differentiation of mesenchymal stem cells from bone marrow and adipose tissue of adult dogs.] Estudo comparativo da diferenciação osteogênica das células tronco mesenquimais da medula óssea e do tecido adiposo de cães adultos. Pesquisa Veterinária Brasileira 36(Supl.1):21-32. Departamento de Clínica e Cirurgia, Escola de Veterinária, Universidade Federal de Minas Gerais, Av. Antônio Carlos 6627, Belo Horizonte, MG 30123-970, Brazil. E-mail: endrigogabellini@yahoo.com.br

The aim of this study was to compare the osteogenic potential of mesenchymal stem cells obtained from bone marrow (BM-MSC) with those extracted from adipose tissue (AT-MSC) of adult dogs. The cells were phenotypically categorized according to the expression of CD29, CD90, CD34 and CD45, and submitted to adipogenic and chondrogenic differentiation for 21 days and osteogenic differentiation for 7, 14 and 21 days. Four groups were formed: BM-MSC in osteogenic medium (1), BM-MSC in basal medium (2), AT-MSC in osteogenic medium (3) and ATMSC in basal medium (4). On days 7, 14 and 21 of osteogenic differentiation, the cultures were submitted to evaluations of MTT conversion in formazan, of alkaline phosphatase activity (AP), of collagen and mineralized matrix synthesis, evaluation of the number of cells per field and there was quantification of the gene transcripts for osterix, bone sialoprotein (BSP), osteonectin (ON) and osteocalcin (OC). Both the cells obtained from bone marrow and those from adipose tissue showed high expression of stem cells markers and low expression of hematopoietic cells markers (lower than 2\%). Besides, they were able to differentiate into osteoblasts, chondrocytes and adipocytes. AT-MSC submitted to osteogenic differentiation showed higher MTT conversion in formazan than BM-MSC, under the same conditions on days 7 and 21. The number of cells per field, the AP activity, the collagen and mineralized matrix synthesis were higher in AT-MSC en differentiation, in relation to BM-MSC under the same conditions in all evaluated times. Expressions of osterix, BSP and OC were predominantly higher in differentiated BMMSC, however the expression of ON was higher AT-MSC differentiated on days 7, 14 and 21. In conclusion, AT-MSC present higher osteogenic potential than BM-MSC when extracted from adult dogs.

INDEX TERMS: Mesenchymal stem cells, osteogenic differentiation, dogs.
\end{abstract}

\footnotetext{
${ }^{1}$ Recebido em 15 de maio de 2015.

Aceito para publicação em 18 de janeiro de 2016

${ }^{2}$ Núcleo de Células Tronco e Terapia Celular Animal (NCT-TCA), Departamento de Clínica e Cirurgia, Escola de Veterinária, Universidade Federal de Minas Gerais (UFMG), Av. Antônio Carlos 6627, Belo Horizonte, MG 30123-970 e Universidade Federal de Uberlândia (UFU), Av. João Naves de Ávila 2121, Santa Mônica, Uberlândia, MG 38408-100, Brasil. *Autor para correspondência: endrigogabellini@yahoo.com.br

$\underline{3}$ Departamento de Medicina Veterinária, Centro de Ciências Agrárias (CCA), Universidade Federal do Espírito Santo (UFES), Alto Universitário, Cx. Postal 16, Alegre, ES 29500-000, Brasil.

${ }^{4}$ Departamento de Bioquímica e Imunologia, Instituto de Ciências Biológicas, UFMG, Av. Antônio Carlos 6627, Belo Horizonte, MG 30123-970, Brasil.
}

RESUMO.- 0 objetivo deste estudo foi comparar o potencial osteogênico das células tronco mesenquimais extraídas da medula óssea (CTM-MO) com as do tecido adiposo (CTM-AD) de cães adultos. As células foram caracterizadas fenotipicamente quanto à expressão de CD29, CD90, CD34 e CD45 e submetidas à diferenciação adipogênica e condrogênica por 21 dias e osteogênica por 7, 14 e 21 dias. Foram constituídos quatro grupos: 1) CTM-MO em meio osteogênico, 2) CTM-MO em meio basal, 3) CTM-AD em meio osteogênico e 4) CTM-AD em meio basal. Aos 7, 14 e 21 dias de diferenciação osteogênica as culturas 
foram submetidas às avaliações da conversão de MTT em formazan, da atividade da fosfatase alcalina (FA), da síntese de colágeno e de matriz mineralizada, avaliação do número de células por campo e foram quantificados os transcritos gênicos para osterix, sialoproteina óssea (BSP), osteonectina (ON) e osteocalcina (OC). Tanto as células extraídas da medula óssea quanto do tecido adiposo mostraram elevada expressão de marcadores para células tronco e baixa expressão de marcadores de células hematopoiéticas (menor que 2\%). Além disso, foram capazes de se diferenciar em osteoblastos, condrócitos e adipócitos. As CTM-AD submetidas à diferenciação osteogênica mostraram maior conversão do MTT em formazan que as CTM-MO, sob mesmas condições aos 7 e 21 dias. 0 número de células por campo, a atividade da FA, a síntese de colágeno e de matriz mineralizada foram superior nas CTM-AD em diferenciação, em relação às CTM-MO sob as mesmas condições, em todos os tempos estudados. As expressões de osterix, BSP e OC foram predominantemente superiores nas CTM-MO diferenciadas, mas a expressão de ON foi superior nas CTM-AD diferenciadas aos 7, 14 e 21 dias. Conclui-se que as CTM-AD apresentam maior potencial osteogênico que as CTM-MO quando extraídas de cães adultos.

TERMOS DE INDEXAÇÃO: Células tronco mesenquimais, diferenciação osteogênica, cães.

\section{INTRODUÇÃO}

O cultivo celular bem sucedido e o subsequente uso das células para tratamento de diferentes alterações é o propósito das pesquisas na área de terapia celular e, por ser um tema relativamente recente, muitos questionamentos ainda carecem de respostas. Sabe-se que existem diferentes populações de células tronco mesenquimais (CTM), com distinta capacidade proliferativa e de diferenciação no mesmo indivíduo (Payushina et al. 2006). Essas populações são também desigualmente distribuídas nos tecidos, o que determina maior ou melhor potencial proliferativo e de diferenciação das CTM isoladas de locais diferentes no mesmo indivíduo (Strioga et al. 2012). Estudos já mostraram que o potencial osteogênico das CTM pode variar de acordo com o tecido de origem (Dmitrieva et al. 2012), com o local de colheita (Neupane et al. 2008), com a espécie animal (Levi et al. 2011), com o gênero (Aksu et al. 2008) e com a idade (Hell et al. 2012). Portanto, para terapias de regeneração óssea é importante conhecer a melhor fonte de CTM, levando-se em consideração o seu potencial de diferenciação osteogênico.

A medula óssea (Lee et al. 2011) e o tecido adiposo (Vieira et al. 2010) são considerados os principais sítios para obtenção dessas células, devido à maior quantidade e facilidade de colheita e isolamento. No entanto, ainda não se sabe ao certo qual delas é a melhor fonte de CTM para terapias de regeneração óssea. Muitos estudos já foram realizados em humanos e ratos mas, pouco se sabe sobre o potencial osteogênico dessas células em outras espécies como o cão. Alguns pesquisadores demonstram que as CTM oriundas da medula óssea (CTM-MO) apresentam maior potencial osteogênico que as CTM do tecido adiposo (CTM-AD) (Park et al. 2012, Monaco et al. 2012), outros indicam maior potencial osteogênico nas CTM-AD (Lin et al. 2009, Chung et al. 2012) e existem aqueles que mostram potencial osteogênico semelhante entre os dois tipos celulares (Spencer et al. 2012, Ranera et al. 2012). Em cães, os estudos comparativos entre CTM-MO e CTM-AD são escassos. Um deles comparou o potencial osteogênico das células tronco da medula óssea, do tecido adiposo e do cordão umbilical em defeitos ósseos de cães (Kang et al. 2012). Outro estudo comparou a expressão de alguns transcriptos gênicos da diferenciação osteogênica em culturas de CTM-MO e de CTM-AD, mas sem menção à síntese de matriz mineralizada. Ficou comprovado que não há diferença na expressão de Oct3/4 e Sox2 entre CTM-MO e CTM-AD e que a expressão de Nanog é 2,5 vezes maior em CTM-AD que em CTM-MO (Takemitsu et al. 2012).

Assim, o objetivo do presente estudo foi avaliar e comparar quantitativamente o potencial osteogênico das CTM-MO e das CTM-AD de cães adultos, por meio da síntese de matriz mineralizada e da expressão de transcriptos gênicos da diferenciação osteogênica, e sugerir portanto a melhor fonte de CTM para uso nas terapias de regeneração óssea em cães.

\section{MATERIAL E MÉTODOS}

Este estudo foi realizado de acordo com as normas internacionais de bem estar animal após aprovação pelo Comitê de Ética em Experimentação Animal (CETEA) da UFMG (protocolo noo 157/2009).

\section{Colheita de células tronco e caracterização fenotípica}

Foram utilizadas as células tronco da medula óssea e do tecido adiposo de três cães, machos, não castrados, sem raça definida com dois anos de idade e massa corporal média de $18 \mathrm{Kg}$. Para a colheita das amostras, os cães foram submetidos apenas ao jejum sólido de oito horas. Como medicação pré-anestésica, foram empregados 1mg/kg IM de xilazina (Calmiun, Agener União, Brasil) e $15 \mathrm{mg} / \mathrm{kg}$ IM de quetamina (Vetanarcol, Konig, Brasil), na mesma seringa. 0 membro pélvico direito foi submetido à tricotomia desde a coluna lombo-sacra até o tarso e preparado para cirurgia asséptica. A veia cefálica foi canulada e os animais receberam propofol (Fresofol, Fresenius Kabi, Brasil) (3mg/kg IV) para intubação e manutenção anestésica. Como analgésico e anti-inflamatório foi administrado meloxicam (Maxicam, Ouro Fino, Brasil) $(0,2 \mathrm{mg} / \mathrm{kg}$ IM) imediatamente após a indução anestésica.

A coleta da medula óssea foi realizada por punção aspirativa na tibial proximal, pelo acesso medial, entre o ligamento patelar e o ligamento colateral medial, com agulha $16 \mathrm{G}$ com mandril, acoplada a uma seringa de $10 \mathrm{~mL}$ contendo $0,5 \mathrm{~mL}$ de heparina sódica (Parinex, Hipolabor, Brasil) na concentração de 5000 UI/mL. Foi coletado $1 \mathrm{~mL}$ de medula óssea de cada animal, totalizando $3 \mathrm{~mL}$ de amostra final. As amostras de tecido adiposo foram coletadas cirurgicamente, removendo-se o tecido adiposo subcutâneo da região glútea imediatamente acima do trocânter maior. Foi coletado aproximadamente $1 \mathrm{~cm}^{3}$ de tecido adiposo de cada animal totalizando cerca de $3 \mathrm{~cm}^{3}$ de amostra final. Imediatamente após a coleta, as amostras de medula e de tecido adiposo foram colocadas separadamente em tubos falcon de $50 \mathrm{~mL}$ contendo $20 \mathrm{~mL}$ de meio de cultura Dulbecco's Modiffed Eagle Medium baixa glicose (DMEM, Gibco, USA), à temperatura ambiente e encaminhadas para sala de cultura para realização dos protocolos de extração 
para cada tipo de tecido. A amostra de medula óssea foi centrifugada por 10 minutos a 1400rpm e levada para capela de fluxo laminar para manipulação asséptica. 0 sobrenadante foi desprezado e o pellet de células foi ressuspenso em $20 \mathrm{~mL}$ de meio de cultura para células tronco mesenquimais (meio basal), DMEM com baixa glicose enriquecido com gentamicina $(60 \mu \mathrm{g} / \mathrm{L})$, penicilina $(100 \mathrm{U} / \mathrm{mL})$, estreptomicina $(100 \mu \mathrm{g} / \mathrm{mL})$, anfotericina $(25 \mu \mathrm{g} /$ $\mathrm{mL}$ (PSA, Sigma-Aldrich, USA) e 10\% de soro fetal bovino (Sorali, Brasil). Uma alíquota de $2 \mathrm{~mL}$ do meio com as células ressuspensas foi transferida para cada garrafa de cultivo celular T75 (Techno Plastic Products in Trasadingen, Germany) e $8 \mathrm{~mL}$ de meio foram adicionados em cada garrafa. Foram feitas dez garrafas. Realizou-se homogeneização e as garrafas foram incubadas em estufa a $37^{\circ} \mathrm{C}$ e $5 \%$ de $\mathrm{CO}_{2}$. Após $48 \mathrm{~h}$ as células foram lavadas duas vezes com PBS 0,15 molar para remoção das hemácias e demais células não aderidas. 0 meio de cultivo foi trocado duas vezes por semana.

A extração das células tronco mesenquimais de tecido adiposo foi realizada segundo o protocolo descrito a seguir que foi adaptado de protocolos estabelecidos por Neupane et al. (2008) e Vieira et al. (2010).

As amostras de tecido adiposo foram também manipuladas na capela de fluxo laminar. As amostras foram lavadas duas vezes com PBS 0,15 molar para retirada de restos de sangue e debris celulares. Para digestão do tecido conjuntivo e liberação das células, as amostras foram colocadas em outro tubo falcon de $50 \mathrm{~mL}$ contendo $20 \mathrm{~mL}$ de uma solução estéril de colagenase B (Roche Applied Science, Alemanha) 0,1\% P/V. As amostras foram fragmentadas a partículas menores com tesoura cirúrgica estéril. A tesoura foi introduzida no tubo falcon de $50 \mathrm{~mL}$ e com movimentos de abrir e fechar, o tecido foi fragmentado ao máximo possível. Em seguida a amostra foi encubada em estufa a $37^{\circ} \mathrm{C}$ e $5 \%$ de $\mathrm{CO}_{2}$ durante 45 minutos e a cada 15 minutos a amostra foi vigorosamente agitada para facilitar o processo de digestão. Transcorrido o tempo de digestão, a amostra foi centrifugada por 10 minutos a $1400 \mathrm{rpm}$, o sobrenadante contendo a fração adiposa foi descartado e o pellet foi ressuspenso em $10 \mathrm{~mL}$ PBS 0,15 molar. A amostra foi colocada em outro tubo falcon e centrifugada por 10 minutos a $1400 \mathrm{rpm}$. Após a centrifugação, o sobrenadante foi descartado e o pellet, fração estromal, foi ressuspenso em $20 \mathrm{~mL}$ de meio de cultura basal (DMEM) da mesma forma como descrito para as células extraídas da medula óssea. Uma alíquota de $2 \mathrm{~mL}$ do meio com as células ressupensas foi transferida para cada garrafa de cultivo celular T75 e 8mL de meio foram adicionados em cada garrafa. Foram feitas dez garrafas no total. Realizou-se homogeneização e as garrafas foram incubadas em estufa a $37^{\circ} \mathrm{C}$ e $5 \%$ de $\mathrm{CO}_{2}$. Após $48 \mathrm{~h}$ foi realizada troca parcial do meio de cultura, renovando apenas $5 \mathrm{~mL}$. Após mais $48 \mathrm{~h}$ as células foram lavadas duas vezes com PBS 0,15 molar para remoção de debris e células não aderidas. 0 meio de cultivo foi trocado duas vezes por semana.

Assim que foi atingido 80 a $90 \%$ de confluência, as células de cada grupo foram separadamente repicadas. Para desprendimento das células, as garrafas foram lavadas com $10 \mathrm{~mL}$ de PBS 0,15 molar para retirada dos restos de meio de cultura. Após a lavagem, foram adicionados $1,5 \mathrm{~mL}$ de tripsina e a garrafa foi incubada por 10 minutos em estufa a $37^{\circ} \mathrm{C}$ e $5 \%$ de $\mathrm{CO}_{2}$. Transcorrido o tempo de ação da tripsina a mesma foi inativada com $5 \mathrm{~mL}$ de DMEM enriquecido com $10 \%$ de soro fetal bovino. As garrafas foram então lavadas com o próprio meio para retirada das células e uma alíquota de $1 \mathrm{~mL}$ foi repicada para outra garrafa T75 com mais $9 \mathrm{~mL}$ de meio de cultura. No terceiro repique ambos os tipos celulares foram caracterizados fenotipicamente quanto à expressão de CD90, CD29, CD45 e CD34 e submetidas à diferenciação osteogênica por sete, 14 e 21 dias.
Para a caracterização fenotípica, as células de cada grupo foram submetidas separadamente à ação da tripsina e ressuspensas em $1 \mathrm{~mL}$ de solução PBS $0,15 \mathrm{M}+10 \%$ SFB $+1 \%$ azida sódica à temperatura de $4^{\circ} \mathrm{C}$ para fixação, evitando a internalização dos epítopos de interesse. Elas foram contadas em câmara de Neubauer e plaqueadas na concentração de $1 \times 10^{5}$ células por poço em placas de 96 poços de fundo redondo. Foram feitos dois poços para controle negativo, dois poços para controle de marcação inespecífica só com anticorpo secundário conjugado com FITC (ab6730, Abcam, USA) e dois poços para cada marcador CD90 (ab22541, Abcam, USA), CD29-PE (ab64629, Abcam, USA), CD45 (ab22514, Abcam, USA) e CD34-PE (ab42902, Abcam, USA). Após o plaqueamento, as células foram centrifugadas a 1400rpm durante 10 minutos, o sobrenadante foi descartado e adicionou-se $100 \mu \mathrm{L}$ de anticorpo primário para cada marcador. A placa foi incubada protegida da luz, a $4^{\circ} \mathrm{C}$ por 30 minutos. Nos controles negativos e para marcação inespecífica foram adicionados $100 \mu \mathrm{L}$ de PBS $0,15 \mathrm{M}+3 \%$ BSA. Utilizou-se as diluições de $1 / 5$ para o CD29-PE, 1/10 para o CD34-PE e 1/500 para o CD90 e CD45. Esta diluição foi feita com solução de PBS 0,15M + 3\% BSA. Transcorrido o período de incubação, as células foram centrifugadas por 10 min a $1400 \mathrm{rpm}$ e o sobrenadante foi descartado. As células foram então submetidas a três lavagens com $200 \mu \mathrm{L}$ de PBS $0,15 \mathrm{M}+3 \%$ $\mathrm{BSA}$ a $4^{\circ} \mathrm{C}$ para retirada dos anticorpos não ligados. Em seguida adicionou-se $100 \mu \mathrm{L}$ do anticorpo secundário conjugado com FITC nos poços referentes ao controle de ligação inespecífica, e anticorpos primários não conjugados com fluoróforo CD90 e CD45. Os demais poços, controle negativo, CD29-PE e CD34-PE receberam $100 \mu \mathrm{L}$ de PBS $0,15 \mathrm{M}+3 \% \mathrm{BSA}$ a $4^{\circ} \mathrm{C}$. As células foram incubadas por mais 30 minutos a $4^{\circ} \mathrm{C}$, protegidas da luz. Após o período de incubação as células foram centrifugadas por $10 \mathrm{~min}$ a $1400 \mathrm{rpm}$, o sobrenadante foi descartado e as células foram submetidas a mais três lavagens com $200 \mu \mathrm{L}$ de PBS $0,15 \mathrm{M}+3 \%$ BSA a $4^{\circ} \mathrm{C}$ para retirada dos anticorpos não ligados. Em seguida as células foram ressuspensas em $200 \mu \mathrm{L}$ de PBS $0,15 \mathrm{M}+10 \%$ SFB $+1 \%$ azida sódica a $4^{\circ} \mathrm{C}$, por poço, e imediatamente encaminhadas para leitura no citômetro de fluxo FACScan (Fluorescence Activated Cell Analyser), empregando-se o software Cell Quest, com aquisição de 20000 eventos, tendo como parâmetros FSC e SSC em escala linear e FL1 (para FIFC) e FL2 (para PE) em escala logarítmica. Os dados foram analisados pelo programa WinMDI por gráficos dot plot.

\section{Avaliação da capacidade de diferenciação adipogênica, con- drogênica e osteogênica}

Após a caracterização fenotípica e antes do cultivo em meio de diferenciação, as CTM de cada grupo experimental foram avaliadas quanto à viabilidade celular pelo azul de Tripan. As CTM foram cultivadas em garrafas T75 $\left(1 \times 10^{4}\right.$ células $\left./ \mathrm{cm}^{2}\right)$ com DMEM e no momento do teste foram lavadas com PBS $(0,15 \mathrm{M})$ e submetidas à ação da tripsina. 0 sobrenadante contendo as células foi colhido e centrifugado a $1400 \mathrm{~g}$ por 10 minutos, as células foram ressuspensas em meio basal e coradas pelo azul de Tripan. As células viáveis (transparentes) e inviáveis (em azul) de cada grupo foram quantificadas em câmara de Neubauer.

Para diferenciação adipogênica as células de cada grupo foram submetidas separadamente à ação da tripsina e plaqueadas na densidade de $1 \times 10^{4}$ células $/ \mathrm{cm}^{2}$, em seis repetições em placas de seis poços. Após a obtenção de 60 a $70 \%$ de confluência celular o meio basal foi substituído por meio adipogênico que é constituído do DMEM enriquecido com soro fetal bovino (10\%), dexametasona $(1 \mu \mathrm{M})$, insulina $(10 \mu \mathrm{L} / \mathrm{mL})$, indometacina $(100 \mathrm{mM})$ e isobutilmetilxantina $(500 \mathrm{mM})$. Em seguida as células foram cultivadas a $37^{\circ} \mathrm{C}$ e $5 \%$ de $\mathrm{CO}_{2}$ por 21 dias e o meio de cultura trocado a cada quatro dias. Transcorrido esse período as células foram fi- 
xadas em formalina $10 \%$ por 60 minutos, coradas pela técnica de Oil Red e avaliados por microscopia óptica, para confirmação da diferenciação adipogênica.

Para diferenciação condrogênica as células de cada grupo foram submetidas separadamente à ação da tripsina e $1 \times 10^{5}$ células de cada grupo foram colocadas em tubos falcon de $15 \mathrm{ml}$ e cultivadas em meio basal por 24 horas. Após esse período o meio basal foi substituído por meio condrogênico que é constituído do DMEM enriquecido com soro fetal bovino (1\%), albumina sérica bovina $(0,0125 \mathrm{~g} / \mathrm{mL})$, piruvato $(100 \mu \mathrm{M})$, insulina $(6,25 \mu \mathrm{g} / \mathrm{mL})$, transferrina $(6,25 \mu \mathrm{g} / \mathrm{mL})$, ácido ascórbico $(50 \mu \mathrm{gM})$, dexametasona $(100 \mathrm{nM})$ e TGF- $\beta 1(10 \mathrm{ng} / \mathrm{mL})$. Em seguida as células foram cultivados a $37^{\circ} \mathrm{C}$ e $5 \%$ de $\mathrm{CO}_{2}$ por 21 dias e o meio de cultura trocado a cada quatro dias. Transcorrido esse período os pellets celulares foram fixados em formalina $10 \%$ por 60 minutos e processados pela técnica rotineira de inclusão em parafina. Cortes histológicos com $5 \mu \mathrm{m}$ de espessura foram corados pela técnica de PAS e avaliados por microscopia óptica, para confirmação da diferenciação condrogênica.

Para diferenciação osteogênica as células de cada grupo foram submetidas separadamente à ação da tripsina e plaqueadas na densidade de $1 \times 10^{4}$ células $/ \mathrm{cm}^{2}$, em seis repetições em placas de seis poços (Techno Plastic Products in Trasadingen, Alemanha). Após a obtenção de 60 a 70\% de confluência celular o meio basal foi substituído por meio osteogênico que é enriquecido com ácido ascórbico $(50 \mu \mathrm{g} / \mathrm{mL})$, ß-glicerofosfato (Sigma-Aldrich, USA) $(10 \mathrm{mM})$ e dexametasona (Aché, Brasil) $(0,1 \mu \mathrm{M})$, acrescido de $10 \%$ de soro fetal bovino. Em seguida as células foram cultivadas a $37^{\circ} \mathrm{C}$ e $5 \%$ de $\mathrm{CO}_{2}$ por 21 dias. Ao término desse período as culturas foram fixadas em álcool $70 \%$ por 24 horas, foram coradas pelo método de Von Kossa adaptado de Prophet et al. (1992) e avaliadas por microscopia óptica, para confirmação da diferenciação osteogênica.

\section{Comparação do potencial osteogênico das CTM-AD e CTM-MO \\ Formação dos grupos experimentais. No terceiro repique} as células de cada grupo ou seja, CTM da medula óssea e do tecido adiposo foram distribuídas nos seguintes grupos: 1) CTM-MO em meio osteogênico, 2) CTM-MO em meio basal, 3) CTM-AD em meio osteogênico e 4) CTM-AD em meio basal. As células de cada grupo foram cultivadas em quadruplicata a $37^{\circ} \mathrm{C}$ e $5 \%$ de $\mathrm{CO}_{2}$ por sete, 14 e 21 dias. Transcorridos esses períodos, foram avaliados a conversão do MTT em cristais de formazan, a atividade da fosfatase alcalina, a síntese de colágeno, a área celular e mineralizada por campo e a expressão relativa dos transcritos gênicos para osterix (OSX), sialoproteina óssea (BSP), osteonectina (ON) e osteocalcina (OC) por RT-PCR em tempo real.

Conversão do MTT em formazan e atividade da fosfatase alcalina. Para o teste de conversão do MTT, as CTM de cada grupo foram cultivadas separadamente em placas de 24 poços com DMEM e meio osteogênico e ao término de cada período, submetidas ao teste de conversão do MTT \{brometo de [3-(4,5-dimetiltiazol-2yl)-2,5-difenil tetrazolium]\} em cristais de formazan. 0 meio foi substituído por $210 \mu \mathrm{L}$ de meio osteogênico com soro fetal bovino em cada poço e $170 \mu \mathrm{L}$ de MTT (Invitrogen, USA) $(5 \mathrm{mg} / \mathrm{mL}$ ). A placa foi incubada por duas horas em estufa a $37^{\circ} \mathrm{C}$ e $5 \%$ de $\mathrm{CO}_{2}$. Os cristais de formazan foram observados ao microscópio antes do acréscimo de $210 \mu \mathrm{L}$ de SDS (sódio dodecil sulfato)-10\% $\mathrm{HCl}$ que permaneceu overnight em estufa a $37^{\circ} \mathrm{C}$ e $5 \%$ de $\mathrm{CO}_{2}$. Posteriormente, $100 \mu \mathrm{L}$ de cada poço foram transferidos para placas de 96 poços para análise na leitora de placas com comprimento de onda de 595nm de acordo com Boeloni et al. (2013).

Para avaliação da atividade da fosfatase alcalina, as CTM de cada grupo foram cultivadas separadamente em placas de 24 poços com DMEM e meio osteogênico. Ao término de cada período, as culturas foram lavadas com PBS (0,15 molar). Em cada poço, foram acrescentados $200 \mu \mathrm{L}$ de solução de BCIT/NBT (Zymed Laboratories, EUA). As amostras ficaram duas horas na estufa a $37^{\circ} \mathrm{C}$ e $5 \%$ de $\mathrm{CO}_{2}$ e foram observadas ao microscópio óptico antes do acréscimo de $200 \mu \mathrm{L}$ de SDS (sódio dodecil sulfato)-10\% HCl. Estas amostras permaneceram overnight em estufa a $37^{\circ} \mathrm{C}$ e $5 \%$ de $\mathrm{CO}_{2}$. Posteriormente, $100 \mu \mathrm{L}$ de cada poço foram transferidos para placas de 96 poços para leitura em espectrofotômetro com comprimento de onda de 595nm de acordo com Ocarino et al. (2008).

\section{Síntese de colágeno, porcentagem de células e de matriz mi- neralizada}

Para avaliação da síntese de colágeno, as CTM de cada grupo foram cultivadas separadamente em placas de 24 poços com DMEM e meio osteogênico. Ao término de cada período, as culturas foram lavadas com PBS (0,15 molar). Adicionou-se em seguida, $1 \mathrm{ml}$ de Bouin em cada poço, para fixação e a placa foi incubada por duas horas em estufa a $37^{\circ} \mathrm{C}$ e $5 \%$ de $\mathrm{CO}_{2}$ As placas foram então retiradas da estufa e colocadas overnight a $6^{\circ} \mathrm{C}$ em geladeira. Transcorrido esse período, as placas foram lavadas quatro vezes com água osmose reversa e secas para posterior coloração com Sirius Red durante 30 minutos à temperatura ambiente. 0 excesso do corante foi removido e as células foram lavadas três vezes com solução de $\mathrm{HCl}$ 0,01N e secas. Posteriomente, foram adicionados $300 \mu \mathrm{L}$ de $\mathrm{NaOH} 0,5 \mathrm{M}$ e a placa foi incubada por mais 30 minutos. Em seguida, $100 \mu \mathrm{L}$ de cada poço foram transferidos para placas de 96 poços para leitura em espectrofotômetro com comprimento de onda de 540nm de acordo com Boeloni et al. (2009).

Para a determinação da porcentagem de células e dos nódulos de mineralização por campo, as CTM de cada grupo foram cultivadas separadamente em placas de seis poços com lamínulas (22x22mm) estéreis, com DMEM e meio osteogênico. Ao término de cada período de avaliação, as culturas foram fixadas em álcool $70 \%$ por 24 horas e coradas pelo método de Von Kossa adaptado de Prophet et al. (1992). As porcentagens de células e de área mineralizada por campo foram determinadas com o auxílio de uma ocular micrométrica, contendo gratícula com 121 pontos, em 25 campos, com objetiva de $4 \mathrm{x}$.

\section{Quantificação de transcriptos gênicos da diferenciação oste- ogênica}

Como controle positivo da diferenciação osteogênica, foi utilizado uma cultura primária comercial de osteoblastos caninos (Abcan, MA, USA), que foi descongelada conforme protocolo sugerido pelo fabricante e cultivados em garrafas T75, com os mesmos meios e sob as mesmas condições das CTM-MO e CTM-AD. No terceiro repique após obtenção de 80 a $90 \%$ de confluência, as culturas de osteoblastos foram utilizadas para extração do RNA total e posterior análise da expressão de osterix, sialoproteína óssea, osteonectina e osteocalcina pela técnica de RT-PCR em tempo real.

Para a quantificação relativa dos transcritos gênicos para osterix, sialoproteína óssea e osteocalcina por RT-PCR em tempo real as CTM de cada grupo foram cultivadas em quadruplicata em garrafas T25 com DMEM (meio basal) ou meio osteogênico. Ao término de cada período de avaliação, extraiu-se o RNA total das culturas de cada garrafa com o emprego do Trizol (Invitrogen, USA) seguindo o protocolo recomendado pelo fabricante. O RNA foi solubilizado em água DEPC (Invitrogen, USA) livre de RNAse e imediatamente armazenado a $-80^{\circ} \mathrm{C}$. A concentração de RNA foi determinada pela leitura da absorbância a 260/280 nm, por espectrofotometria. Foram realizadas as reações de transcrição reversa utilizando-se Kit SuperScript ${ }^{\mathrm{TM}}$ III Platinum ${ }^{\circledR}$ Two-Step (Invitrogen, USA). Utilizou-se $1 \mu \mathrm{g}$ de RNA total para a síntese de cDNA com um volume final de $20 \mu \mathrm{L}$. As reações de PCR foram feitas em tempo real, utilizando-se $2 \mu \mathrm{g}$ de cDNA, $5 \mathrm{pM}$ de cada inicia- 
Quadro 1. Lista de genes e sequência de nucleotídeos dos iniciadores para RT-PCR em tempo real

\begin{tabular}{|c|c|c|c|}
\hline $\begin{array}{l}\text { Genes } \\
\text { Referência ou № de acesso }\end{array}$ & $\begin{array}{l}\text { Oligonucleotídios iniciadores } \\
\text { (sequências de nucleotídeos 5' a 3') }\end{array}$ & $\begin{array}{l}\text { Temperatura de } \\
\text { anelamento }\left({ }^{\circ} \mathrm{C}\right)\end{array}$ & $\begin{array}{l}\text { Tamanho do produto } \\
\text { (pares de base) }\end{array}$ \\
\hline Osterix (OSX) & F- ACGACACTGGGCAAAGCAG & 60 & 285 \\
\hline (Neupane et al. 2008) & R- CATGTCCAGGGAGGTGTAGAC & & \\
\hline Sialoproteina óssea (BSP) & F- TTGCTCAGCATTTTGGGAAT & 60 & 295 \\
\hline (Vieira et al. 2010) & R- AACGTGGCCGATACTTAAAGAC & & \\
\hline Osteonectina $(\mathrm{ON})$ & F- GCCTTGGCAGCCCCTCAACA & 60 & 108 \\
\hline (XM_849889.1) & R- CACCTGCACGGGGTTGGCTC & & \\
\hline Osteocalcina (OC) & F- GAGGGCAGCGAGGTGGTGAG & 62 & 134 \\
\hline (Neupane et al. 2008) & R- TCAGCCAGCTCGTCACAGTTGG & & \\
\hline GAPDH & F- CCATCTTCCAGGAGCGAGGAT & 60 & 97 \\
\hline (Vieira et al. 2010) & R- TTCTCCATGGTGGTGAAGAC & & \\
\hline
\end{tabular}

dor e $12,5 \mu \mathrm{L}$ do reagente syber Green (Invitrogen, USA) em um volume final de $25 \mu \mathrm{L}$ de reação por poço, no aparelho 7500 Real Time PCR Sistem (Applied Biosystems, USA). Os parâmetros utilizados para amplificação foram: $50^{\circ} \mathrm{C}$ por 120 segundos, $95^{\circ} \mathrm{C}$ por 150 segundos e 45 ciclos, $95^{\circ} \mathrm{C}$ por 15 segundos e $60^{\circ} \mathrm{C}$ por 30 segundos. Os iniciadores foram pesquisados na literatura ou delineados com base na sequência do mRNA Canis familiares (Qua-

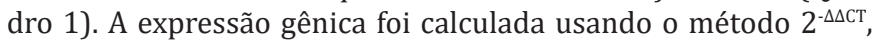
onde os resultados obtidos para cada grupo foram comparados quantitativamente após a normalização baseada na expressão de gliceraldeído-3-fosfato desidrogenase (GAPDH) Canis familiares. Os níveis de expressão obtidos nas culturas de osteoblastos foram utilizados como controle positivo da diferenciação osteogênica e como padrão de expressão no cálculo da expressão relativa de cada transcrito.

\section{Análise estatística}

Realizou-se análise de variância (ANOVA) e para cada variável, foram determinados a média e o desvio padrão. As médias foram comparadas pelo teste SNK utilizando o programa Graphpad Instat3. As alterações na expressão medidas pelo RT-PCR em tempo real foram comparadas pelo teste de SNK após transformação logarítmica dos dados. Diferenças foram consideradas significativas para $\mathrm{p}<0,05$ (Sampaio 1998).

\section{RESULTADOS}

Caracterização fenotípica das CTM e comprovação do potencial de diferenciação em osteoblatos, adipócitos e condroblastos

Os protocolos utilizados para isolamento, cultivo e expansão das CTM-MO e CTM-AD foram eficientes e permitiram a manutenção das culturas até a sexta passagem quando as células foram descartadas. As CTM-MO e as CTM-AD apresentaram morfologia alongada, fusiforme, semelhante à morfologia de fibroblastos (Fig.1).

A caracterização fenotípica por citometria de fluxo das CTM-MO mostrou baixa expressão de marcadores de células hematopoiéticas CD45 (1,45\%) e CD34 (1,53\%) e alta expressão de marcadores de células tronco CD90 $(80,04 \%)$ e CD29 (96\%). Resultado semelhante foi obtido após a caracterização fenotípica por citometria de fluxo das CTM-AD, isso é, baixa expressão de marcadores de células hematopoiéticas CD45 (1,54\%) e CD34 (0,88\%) e alta expressão de marcadores de células tronco CD90 $(60,94 \%)$ e CD29 (77,08\%).

As CTM-AD e CTM-MO apresentaram a formação de nódulos de mineralização após 21 dias de cultivo em meio os-

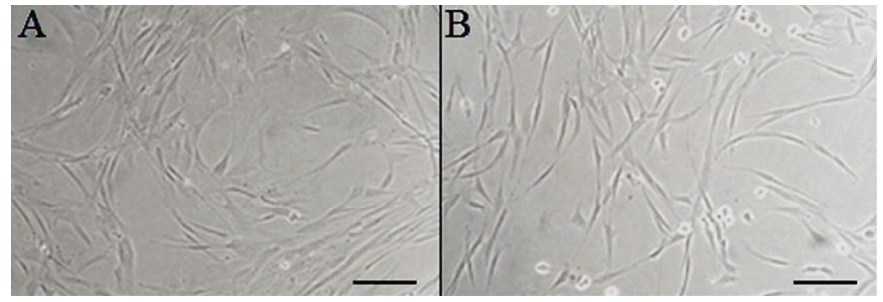

Fig.1. (A) Fotomicroscopia de contraste de fase das células tronco mesenquimais extraídas de medula óssea e (B) do tecido adiposo de cães. Observar a morfologia alongada e fusiforme das células. Barra $=70 \mu \mathrm{m}$.

teogênico, caracterizando sucesso na diferenciação osteogênica (Fig.2). Verificou-se a formação de vesículas lipídicas com aspecto birrefringente e coloração avermelhada por Sudam no interior do citoplasma das CTM-MO e CTM-AD após 21 dias de cultivo em meio adipogênico o que caracteriza a diferenciação adipogênica dessas células (Fig.2). Após 21 dias de cultivo em meio condrogênico, foi possível observar a diferenciação das CTM-MO e CTM-AD em condrócitos com o acúmulo de proteoglicanos corados em violeta vivo no interior do citoplasma e na matriz extracelular (Fig.2).

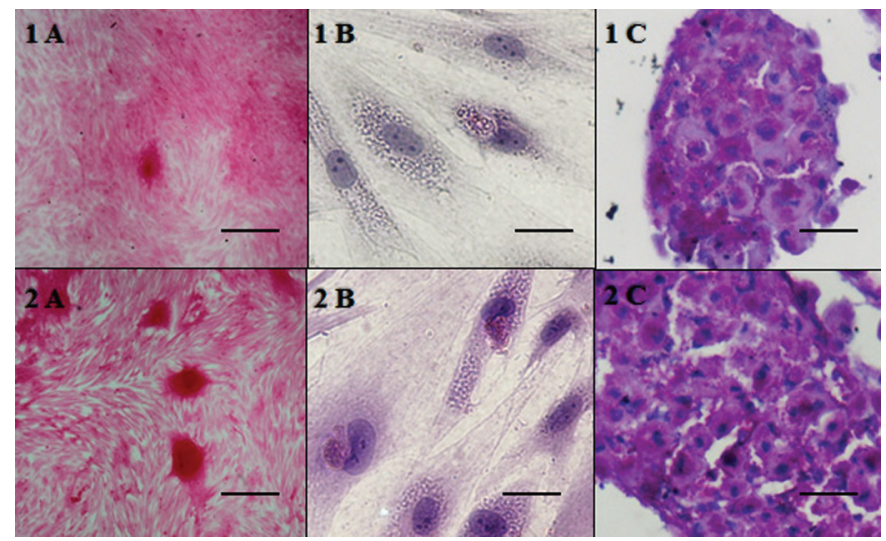

Fig.2. Cultura de células tronco mesenquimais extraídas da medula (1) e do tecido adiposo (2) de cães submetida à diferenciação osteogênica (A), adipogênica (B) e condrogênica (C) por 21 dias. Observar nas imagens $1 \mathrm{~A}$ e $2 \mathrm{~A}$ os nódulos de mineralização corados em vermelho pela técnica de Von Kossa; nas imagens $1 \mathrm{~B}$ e $2 \mathrm{~B}$ as vesículas lipídicas com aspecto birrefringente e coloração avermelhada no interior das células coradas pela técnica Oil Red e nas imagens $1 \mathrm{C}$ e $2 \mathrm{C}$ os proteoglicanos corados em violeta vivo pela técnica de PAS. Barras das imagens $1 \mathrm{~A}$ e $2 \mathrm{~A}=350 \mu \mathrm{m}$ e das imagens $1 \mathrm{~B}, 2 \mathrm{~B}, 1 \mathrm{C}$ e $2 \mathrm{C}=8,75 \mu \mathrm{m}$. 
Comparação da diferenciação osteogênica das CTM-MO e CTM-AD

Conversão do MTT em formazan e atividade da fosfatase alcalina. Em todos os grupos houve aumento da capacidade de conversão do MTT em cristais de formazan ao longo do tempo de cultivo, independente do meio utilizado (Fig.3). As CTM mantidas em meio basal mostraram maior capacidade de conversão de MTT que as mantidas em meio osteogênico, aos 14 e 21 dias de cultivo, já aos sete dias, as CTM mantidas em meio osteogênico mostraram maior conversão de MTT que as mantidas em meio basal (Fig.3). Quando mantidas em meio basal, as CTM-AD mostraram maior conversão de MTT que as CTM-MO, em todos os tempos estudados (Fig.3). Em meio osteogênico, as CTM-AD mostraram maior conversão de MTT que as CTM-MO aos sete e 21 dias de cultivo e nenhuma diferença foi observada aos 14 (Fig.3).

As CTM mantidas em meio osteogênico mostraram maior atividade da fosfatase alcalina que as mantidas em meio basal, em todos os tempos estudados (Fig.4). Independente do meio de cultura utilizado, as CTM-AD mostraram maior atividade da fosfatase alcalina que as CTM-MO, em todos os tempos estudados (Fig.4).

Síntese de colágeno, porcentagem de células e de matriz mineralizada. Em todos os grupos houve aumento da percentagem de células por campo, ao longo do cultivo, independente do meio utilizado. As CTM-MO mantidas em meio basal mostraram maior celularidade que as mantidas
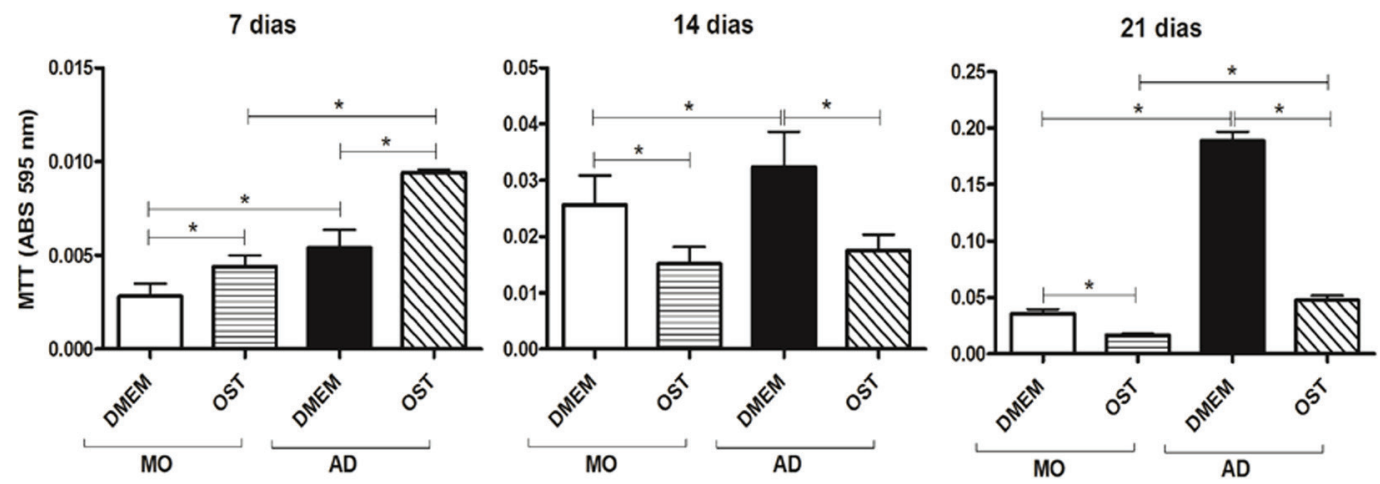

Fig.3. Média e desvio padrão da conversão do MTT em cristais de formazan em culturas de CTM-MO e CTM-AD de cães, mantidas em meio basal (DMEM) e meio osteogênico (OST) por sete, 14 e 21 dias. * $(\mathrm{P}<0,05)$.
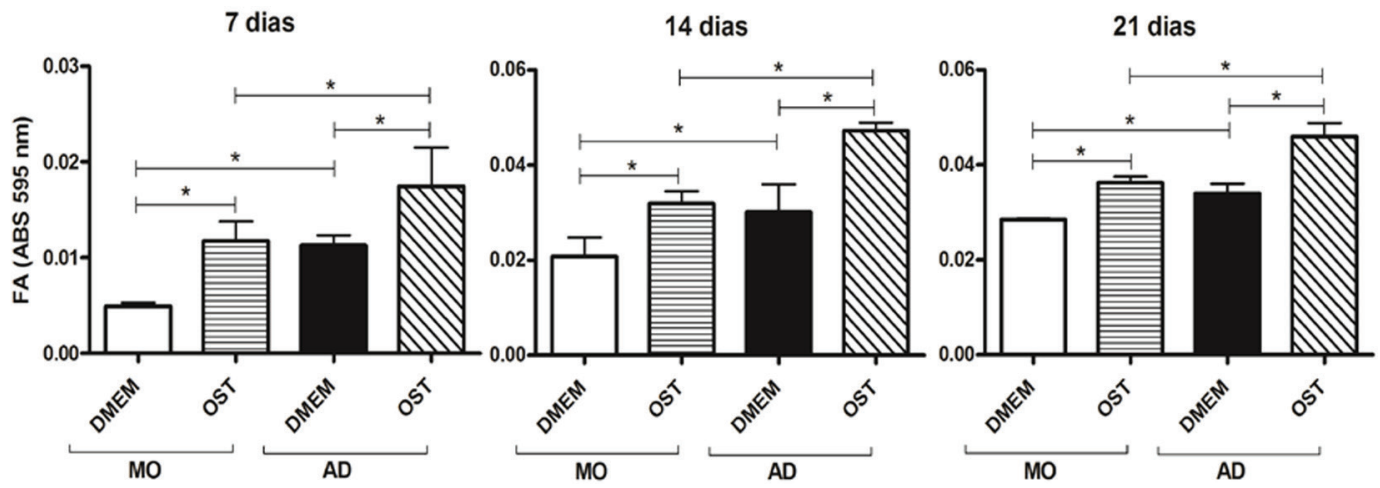

Fig.4. Média e desvio padrão da atividade da fosfatase alcalina em culturas de CTM-MO e CTM-AD de cães, mantidas em meio basal (DMEM) e meio osteogênico (OST) por sete, 14 e 21 dias. * $(\mathrm{P}<0,05)$.
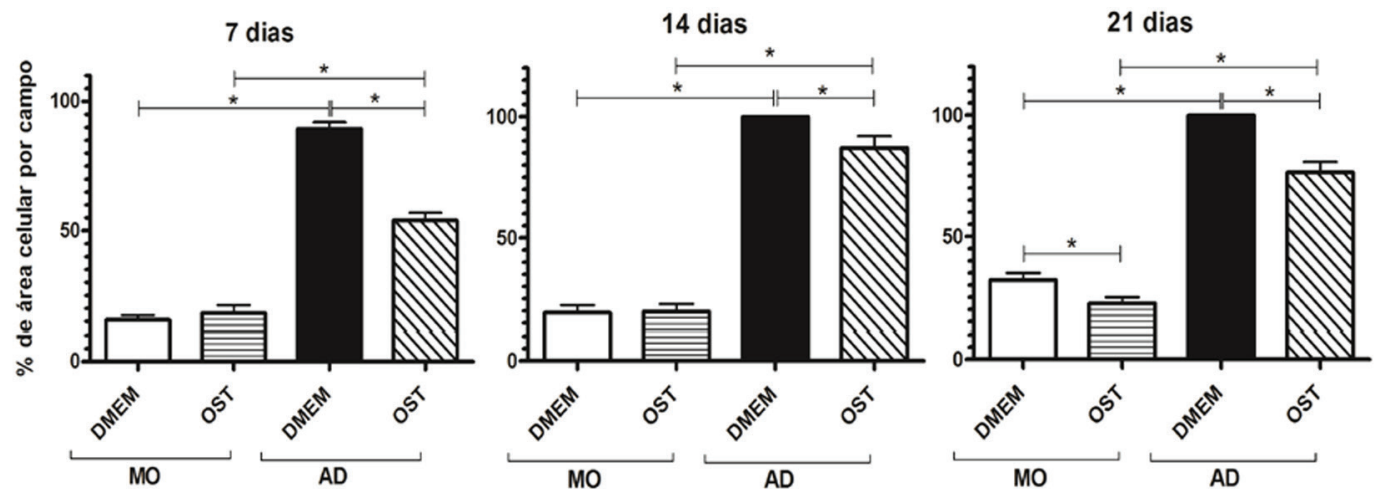

Fig.5. Porcentagem média e desvio padrão da área celular por campo em culturas de CTM-MO e CTM-AD de cães, mantidas em meio basal (DMEM) e meio osteogênico (OST) por sete, 14 e 21 dias. $*(\mathrm{P}<0,05)$. 


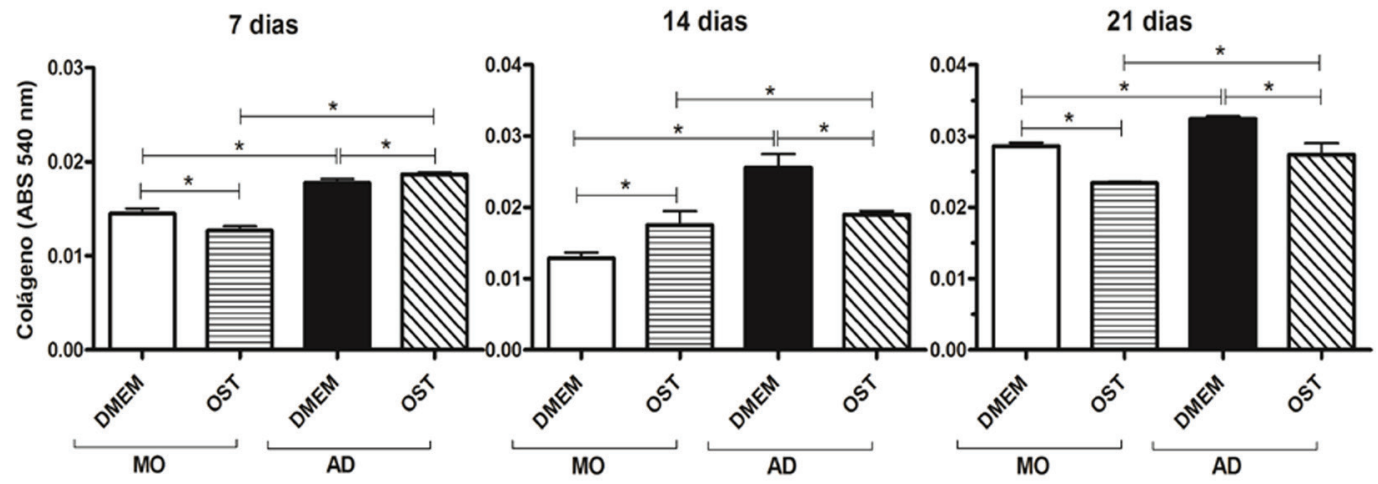

Fig.6. Média e desvio padrão do colágeno em culturas de CTM-MO e CTM-AD de cães, mantidas em meio basal (DMEM) e meio osteogênico (OST) por sete, 14 e 21 dias. ${ }^{*}(\mathrm{P}<0,05)$.

em meio osteogênico, aos 21 dias de cultivo, já aos sete e 14, nenhuma diferença foi observada (Fig.5). As CTM-AD mantidas em meio basal mostraram maior celularidade que as mantidas em meio osteogênico, em todos os tempos estudados (Fig.5). As CTM-ADs mostraram maior celularidade que as CTM-MOs em todos os tempos estudados independente do meio de cultura utilizado (Fig.5).

Em todos os grupos houve um aumento na síntese de colágeno ao longo do tempo de cultivo, independente do tipo de meio utilizado. As CTM-MO mantidas em meio basal mostraram maior dosagem de colágeno que as mantidas em meio osteogênico, aos sete e 21 dias de cultivo, já aos 14 dias, maior síntese de colágeno foi observada nas CTM-MO mantidas em meio osteogênico (Fig.6). As CTM-AD mantidas em meio basal mostraram maior síntese de colágeno que as mantidas em meio osteogênico, aos 14 e 21 dias de cultivo, já aos sete dias, maior síntese de colágeno foi observada nas CTM-AD mantidas em meio osteogênico (Fig.6). As CTM-AD mostraram maior síntese de colágeno que as CTM-MO em todos os tempos estudados, independente do meio de cultivo utilizado (Fig.6).

As CTM-MO submetidas à diferenciação osteogênica formaram apenas um nódulo de mineralização aos 21 dias de cultivo em todos os campos avaliados (Fig.2, 7 e 8). As CTM-AD submetidas à diferenciação osteogênica formaram nódulos de mineralização em todos os tempos estudados e mostraram aumento na porcentagem de área mineralizada por campo, ao longo do tempo de cultivo (Fig.7 e 8). Não houve, em nenhum dos tempos estudados, formação de nódulos de mineralização nas CTM-AD e CTM-MO mantidas em meio basal (Fig.7 e 8). As CTM-AD em meio osteogênico mostraram maior área mineralizada por campo que as CTM-MO sob as mesmas condições, em todos os tempos estudados (Fig.7 e 8).

Transcriptos gênicos da diferenciação osteogênica. Independente de sua origem, as CTM mantidas em meio osteogênico mostraram maior expressão de osterix do que as mantidas em meio basal, em todos os tempos estudados (Fig.9). As CTM-AD e CTM-MO submetidas à diferenciação osteogênica também mostraram maior expressão de osterix que os osteoblastos, exceção feita as CTM-MO aos 21 dias que mostraram expressão de osterix discretamente inferior a dos osteoblastos (Fig.9). Não foi observada diferença na expressão de osterix pelas CTM-MO e CTM-AD

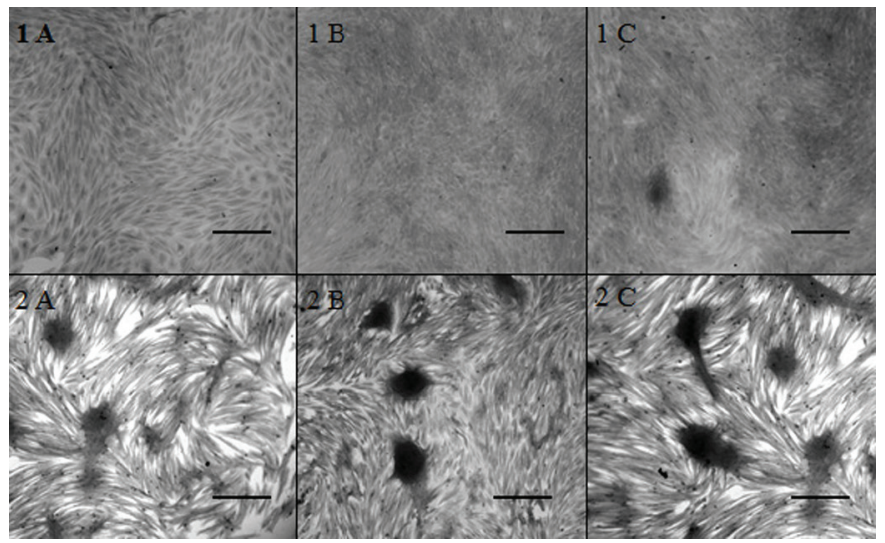

Fig.7. Cultura de células tronco mesenquimais extraídas da medula (1) e do tecido adiposo (2) de cães submetida à diferenciação osteogênica por sete (A), 14 (B) e 21 (C) dias. Observar aumento crescente da área de matriz mineralizada durante o cultivo, representada por nódulos escuros, corados pela técnica de Von Kossa. 0 grupo células tronco extraídas do tecido adiposo (2) apresentou maior área de matriz mineralizada quando comparado com o grupo células tronco extraídas da medula óssea (1) durante todos os tempos estudados. Barra $=350 \mu \mathrm{m}$

mantidas em meio basal, em nenhum dos tempos estudados (Fig.9). Aos 21 dias de cultivo, as CTM-AD submetidas à diferenciação osteogênica mostraram maior expressão de osterix que as CTM-MO sob as mesmas condições. Já aos sete e 14 dias, a maior expressão de osterix foi observada nas CTM-MO (Fig.9).

As CTM mantidas em meio osteogênico mostraram maior expressão de sialoproteína óssea do que as mantidas em meio basal, exceção feita as CTM-MO aos 14 dias que não mostraram diferença na expressão de sialoproteína quando cultivadas em meio basal e em meio osteogênico (Fig.10). Os níveis de expressão de sialoproteína óssea apresentados pelas CTM-MO e CTM-AD submetidas à diferenciação osteogênica não alcançaram os níveis osteoblásticos de expressão de sialoproteína óssea, em nenhum dos tempos estudados (Fig.10). As CTM-MO mantidas em meio basal mostraram maior expressão de sialoproteína óssea que as CTM-AD sob mesmas condições, aos sete dias de cultivo, mas nenhuma diferença foi observada aos $14 \mathrm{e}$ 21 (Fig.10). Aos 14 dias de cultivo, as CTM-AD submetidas 
à diferenciação osteogênica mostraram maior expressão de sialoproteía óssea que as CTM-MO sob mesmas condições, já aos sete e 21 dias, a maior expressão de sialoproteía óssea foi observada nas CTM-MO (Fig.10).

Independente de sua origem, as CTM mantidas em meio osteogênico mostraram maior expressão de osteonectina que as mantidas em meio basal, em todos os tempos estudados. As CTM-AD e CTM-MO submetidas à diferenciação osteogênica também mostraram maior expressão de osteonectina que os osteoblastos, exceção feita as CTM-MO aos 21 dias que mostraram uma expressão de osteonectina inferior a dos osteoblastos (Fig.11). Não foi observada diferença na expressão de osteonectina pelas CTM-MO e CTM-AD mantidas em meio basal, em nenhum dos tempos estudados (Fig.11). As CTM-AD submetidas à diferenciação osteogênica mostraram maior expressão de osteonectina que as CTM-MO sob as mesmas condições, em todos os tempos estudados (Fig.11).

Independente de sua origem, as CTM mantidas em meio osteogênico mostraram maior expressão de osteocalci-
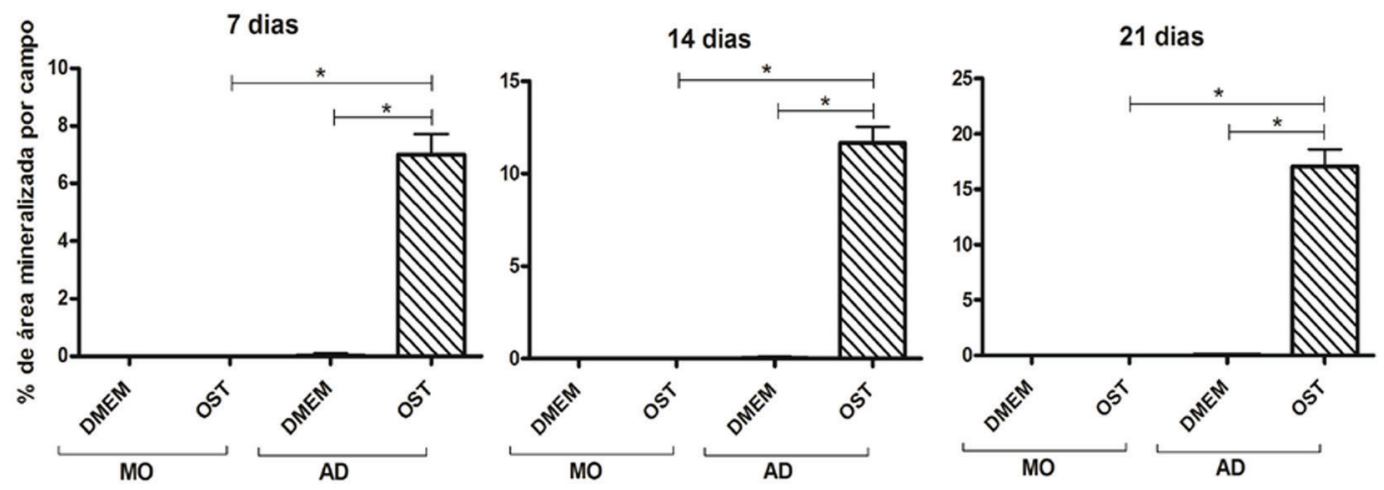

Fig.8. Média e desvio padrão da área de matriz mineralizada por campo em culturas de CTM-MO e CTM-AD de cães, mantidas em meio basal (DMEM) e meio osteogênico (OST) por sete, 14 e 21 dias. ${ }^{*}(\mathrm{P}<0,05)$.
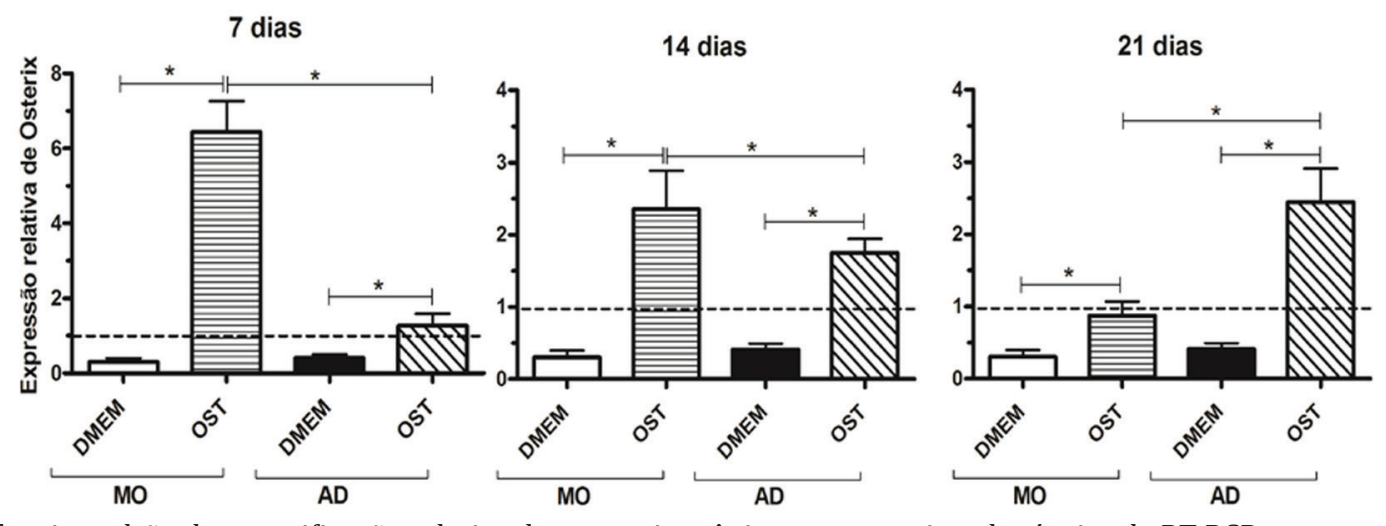

Fig.9. Média e desvio padrão da quantificação relativa do transcrito gênico para osterix pela técnica de RT-PCR em tempo real em culturas de CTM-MO e CTM-AD de cães, mantidas em meio basal (DMEM) e meio osteogênico (OST) por sete, 14 e 21 dias. Os dados estão expressos em relação ao osteoblasto canino mantido em meio basal (DMEM) (linha tracejada). * $(\mathrm{P}<0,05)$.
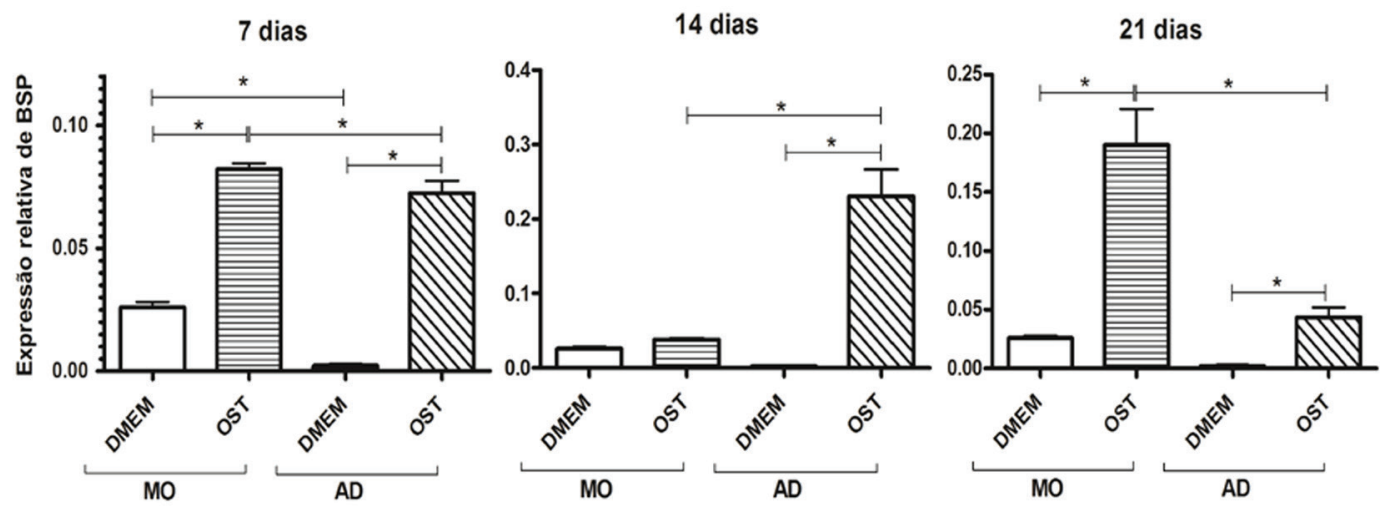

Fig.10. Média e desvio padrão da quantificação relativa do transcrito gênico para sioloproteína óssea (BSP) pela técnica de RT-PCR em tempo real em culturas de CTM-MO e CTM-AD de cães, mantidas em meio basal (DMEM) e meio osteogênico (OST) por sete, 14 e 21 dias. Os dados estão expressos em relação ao osteoblasto canino mantido em meio basal (DMEM), o valor de expressão do osteoblasto foi considerado igual a um. $*(\mathrm{P}<0,05)$. 

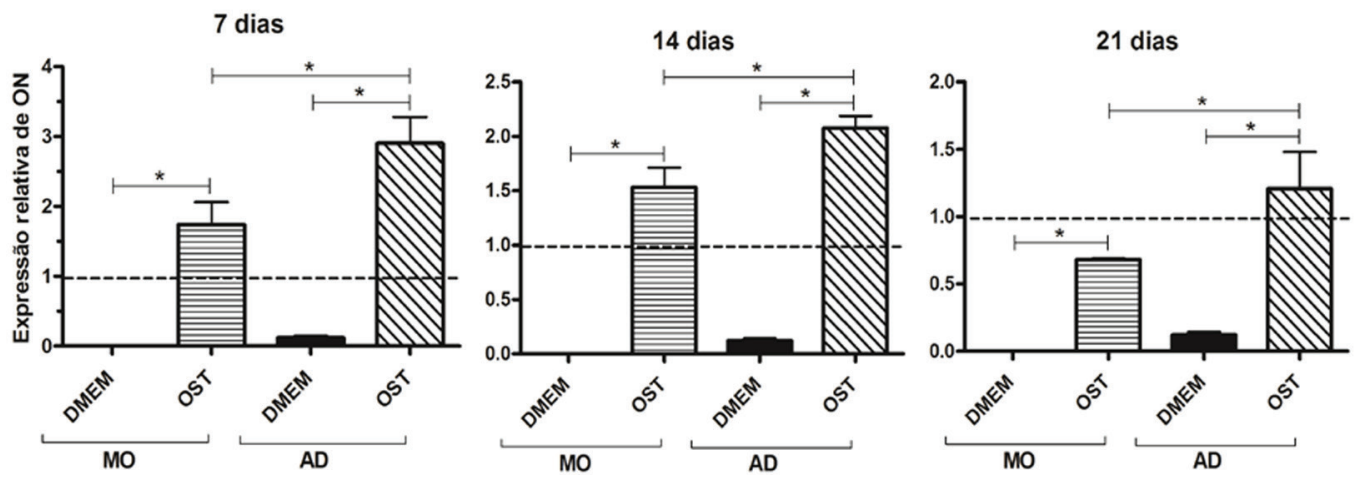

Fig.11. Média e desvio padrão da quantificação relativa do transcrito gênico para osteonectina (ON) pela técnica de RT-PCR em tempo real em culturas de CTM-MO e CTM-AD de cães, mantidas em meio basal (DMEM) e meio osteogênico (OST) por sete, 14 e 21 dias. Os dados estão expressos em relação ao osteoblasto canino mantido em meio basal (DMEM). (linha tracejada). * $(\mathrm{P}<0,05)$.
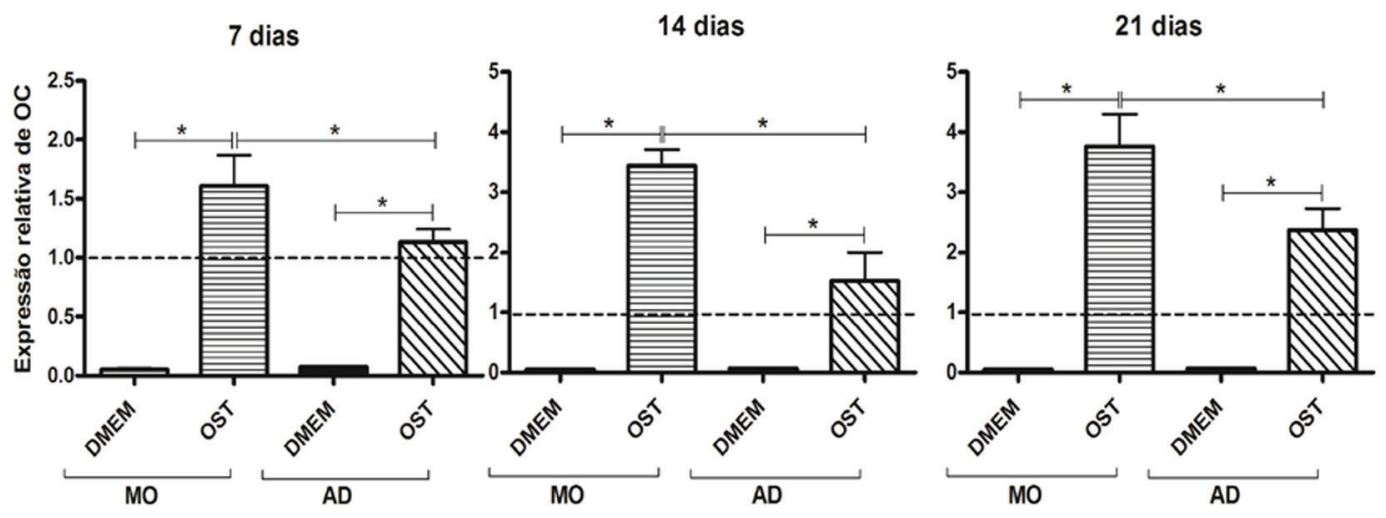

Fig.12. Média e desvio padrão da quantificação relativa do transcrito gênico para osteocalcina (OC) pela técnica de RT-PCR em tempo real em culturas de CTM-MO e CTM-AD de cães, mantidas em meio basal (DMEM) e meio osteogênico (OST) por sete, 14 e 21 dias. Os dados estão expressos em relação ao osteoblasto canino normal mantido em meio basal (DMEM). (linha tracejada). *(P<0,05).

na que as mantidas em meio basal e que os osteoblastos, em todos os tempos estudados (Fig.12). Não foi observada diferença na expressão de osteocalcina pelas CTM-MO e CTM-AD mantidas em meio basal, em nenhum dos tempos estudados (Fig.12). As CTM-MO submetidas a diferenciação osteogênica mostraram maior expressão de osteocalcina que as CTM-AD sob as mesmas condições de cultivo, em todos os tempos estudados (Fig.12).

\section{DISCUSSÃO}

A forma alongada semelhante a fibroblasto apresentada pelas CTM-MO e CTM-AD e sua capacidade de diferenciação em osteoblastos, adipócitos e condrócitos, mostram sucesso no isolamento das células tronco mesenquimais (CTM), critérios esses já definidos pela International Society for Cellular Therapy, como padrão para a comprovação de que a cultura é constituída por CTM (Dominici et al. 2006). A alta expressão de marcadores de células tronco e a baixa expressão de marcadores de células hematopoiéticas observadas no presente estudo, confirmam o sucesso no isolamento das CTM a partir de amostras de medula óssea e de tecido adiposo. Esse padrão de expressão é mundialmente aceito como característico das células tronco mesenquimais (Dominici et al. 2006, Aksu et al. 2008, Levi et al. 2011, Martinello et al. 2011). A International Society for Cellular Therapy definiu que as CTM devem expressar marcadores como CD105, CD73 e CD90 e não expressar os marcadores de células hematopoiéticas (Dominici et al. 2006). A alta expressão de CD90, marcador de CTM, e baixa expressão de CD45 e CD34, marcadores de células hematopoiéticas, observadas nas culturas do presente estudo, sugerem o isolamento de CTM e excluem a possibilidade de isolamento de células tronco hematopoiética, especialmente na cultura extraída da medula óssea. De forma semelhante a elevada expressão de CD29, marcador de CTM não é expresso por fibroblastos caninos (Lee et al. 2011), corrobora com o isolamento de CTM e exclui a possibilidade do isolamento de fibroblastos, principalmente das culturas extraídas do tecido adiposo. Outros marcadores de CTM podem também ser utilizados em cães como CD44 (Vieira et al. 2010), CD33, CD105, CD184, OCT4 (Seo et al. 2009), CD140a, CD117 (Martinello et al. 2011), CD56, CD146, CD271(Rozemuller et al. 2010), mas não haviam, na época do experimento, anticorpos específicos para cão disponíveis no mercado.

A menor conversão de MTT em cristais de formazan observada nas CTM submetidas à diferenciação osteogênica no presente estudo quando comparadas às CTM cultivadas em meio basal, sugerem menor atividade mitocondrial nos grupos submetidos à diferenciação, o que também foi observado em CTM de ratos (Boeloni et la. 2013) e de humanos (Li \& Sun 2011). Isso pode ter ocorrido devido ao menor metabolismo dos osteoblastos, que são as célu- 
las diferenciadas, quando comparado com as CTM indiferenciadas (Datta et al. 2008) mas também, pela menor quantidade de células presente nos grupos submetidos à diferenciação osteogênica como observado neste estudo, apesar do número inicial de células ter sido inicialmente padronizado para todos os grupos. Com a progressão dos estágios de diferenciação há redução da capacidade proliferativa da célula e um deslocamento da atividade celular para a síntese de proteínas específicas da célula diferenciada e dos componentes da matriz extracelular (Payushina et al. 2006).

A maior conversão de MTT em cristais de formazan e a maior celularidade observadas nas culturas de CTM-AD quando submetidas à diferenciação, sugere maior atividade dessas células em relação às CMT-MO sob as mesmas condições. Esta pode ser uma das vantagens do uso das CTM-AD, visto que uma célula mais ativa pode produzir mais matriz extracelular, como foi o caso quando da avaliação da matriz mineralizada, favorecendo assim a regeneração óssea quando utilizada in vivo para esse fim.

0 aumento gradual e progressivo da atividade da fosfatase alcalina durante o processo de diferenciação osteogênica em ambos os tipos celulares CTM-MO e CTM-AD, sugere sucesso na diferenciação osteogênica dessas células. A maior atividade da FA observada nas CTM-AD em relação às CTM-MO indica maior potencial osteogênico das CTM-AD, visto que a FA é um dos marcadores mais utilizados na diferenciação osteogênica in vitro (Eslaminejad \& Taghiyar 2010). A FA é uma enzima presente na membrana do osteoblasto e que participa da síntese e mineralização da matriz óssea (Datta et al. 2008). No processo de diferenciação osteogênica, sua expressão pode aumentar em até 27 vezes, sendo considerada um marcador precoce da diferenciação osteogênica expresso em pré-osteoblastos e osteoblastos (Kassem et al. 2008).

A maior síntese de colágeno e a maior área de matriz mineralizada observadas nas culturas de CTM-AD em relação às CTM-MO mantidas em meio osteogênico, demonstram maior capacidade de produção de matriz extracelular das CTM-AD, em comparação com as CTM-MO sob as mesmas condições de cultivo. 0 colágeno I é o principal constituinte da matriz óssea orgânica representando cerca de $90 \%$ de sua composição, podendo ser expresso por células osteoprogenitoras, pré-osteoblastos e osteoblastos (Nakashima et al. 2002). A formação de nódulos de mineralização a partir do sétimo dia de cultivo nas CTM-AD mantidas em meio osteogênico, confirma a diferenciação dessas células. Após a diferenciação osteogênica as CTM adquirem forma cuboidal ou poligonal semelhante aos osteoblastos e se agrupam concentricamente formando nódulos mineralizados (Eslaminejad \& Taghiyar 2010). Esses nódulos são considerados indicadores de diferenciação osteogênica "in vitro" (Chung et al. 2012, Spencer et al. 2012) e sua quantificação é a forma mais fidedigna de avaliar a osteogênese "in vitro", visto que a produção de matriz mineralizada, não indica apenas a fase final da diferenciação osteogênica, mas também a atividade metabólica das células diferenciadas (Bruedigam et al. 2011).

O aumento na expressão de osterix encontrado nas cul- turas de CTM-MO e CTM-AD submetidas ao protocolo de diferenciação é outro importante indicativo da diferenciação osteogênica. 0 osterix é um fator de transcrição imprescindível no processo de diferenciação osteogênica e atua na transformação dos pré-osteoblastos em osteoblastos maduros, finalizando assim o processo de diferenciação (Franceschi et al. 2009). 0 aumento da expressão de osterix pelas CTM submetidas à diferenciação osteogênica já foi relatado em estudos com ratos e humanos, sendo também considerado um marcador da diferenciação osteogênica em cães (Neupane et al. 2008).

0 aumento da expressão de proteínas não colagênicas, como a sialoproteina óssea (BSP), osteonectina (ON) e osteocalcina (OC) durante o processo de diferenciação observado no presente estudo, comprova o estágio final da diferenciação osteogênica das CTM-MO e das CTM-AD. As proteínas não colagênicas da matriz são consideradas marcadores fidedignos de diferenciação osteogênica e estão intimamente relacionados com a produção e mineralização da matriz extracelular. A BSP é uma das proteínas responsáveis pelo início do processo de nucleação e deposição de hidroxiapatita na matriz óssea. 0 aumento na sua expressão reflete uma fase final da diferenciação e início de mineralização da matriz. A sialoproteina óssea pode ser expressa por pré-osteoblastos e osteoblastos (Datta et al. 2008). 0 aumento da sua expressão também já foi relatado durante o processo de diferenciação osteogênica de CTM-AD em cães (Vieira et al. 2010). A osteocalcina é uma glicoproteína específica do tecido ósseo que atua promovendo a mineralização da matriz. Ela é expressa por osteoblastos e reflete também o final da diferenciação e da maturação da matriz óssea e é considerada o marcador tardio mais específico da diferenciação osteogênica (Nakashima et al. 2002). 0 aumento crescente de sua expressão é característico do processo de diferenciação osteogênica de CTM-MO e CTM-AD (Chung et al. 2012). A osteonectina também está relacionada com a mineralização da matriz no estágio final de diferenciação (Nakashima et al. 2002).

Embora as culturas de CTM-MO, sob diferenciação osteogênica, tenham demonstrado maior expressão de osterix, sialoproteina óssea e de osteocalcina em relação às CTM-AD, isso não promoveu maior osteogênese "in vitro", caracterizada pela síntese de matriz mineralizada. A quantificação dos transcritos gênicos para determinadas proteínas como a sialoproteína óssea e a osteocalcina é um importante indicativo de sua síntese, no entanto, não garante que essas proteínas estejam de fato sendo sintetizadas. Fatores relacionados com a exportação do RNA mensageiro (mRNA) do núcleo para o citoplasma, com a estabilização mRNA para que ele chegue íntegro no local de tradução e fatores relacionados diretamente com a tradução podem fazer com que um mRNA não seja traduzido em proteína (Fabian et al. 2010).

Em ensaios realizados com as CTM dos mesmos cães deste estudo, porém ainda na fase de crescimento ou seja, com quatro meses de idade, observou-se que as CTM-MO foram as que apresentaram maior diferenciação osteogênica (dados não publicados). É provável que essa diferença no potencial osteogênico das CTM, tenha sido decorrente 
do fato de que no animal em crescimento, o metabolismo ósseo é acelerado, principalmente no que diz respeito à diferenciação dos osteoblastos para a síntese de matriz óssea, o que poderia justificar a maior diferenciação osteogênica das CTM da medula óssea, nesta fase. Dessa forma, fica evidente que a idade do cão pode influenciar na capacidade de diferenciação das CTM-MO. Em ratos, as CTM-MO também tem seu potencial osteogênico comprometido pela idade (Hell et al. 2012) e pela presença de doenças óssea ou endócrina (Boeloni et al. 2013). A maior diferenciação osteogênica aliada à menor variação do potencial osteogênico, são algumas das razões, que justificam a utilização das CTM do tecido adiposo em defeitos ósseos. Mas em cães, a eficácia do uso das células tronco do tecido adiposo em defeitos ou doenças ósseas ainda merece ser investigada.

\section{CONCLUSÃO}

As culturas de CTM-AD apresentam maior potencial osteogênico "in vitro" que as de CTM-MO quando extraída de cães adultos.

Agradecimentos.- Os autores agradecem à FAPEMIG pelo financiamento do projeto de pesquisa e ao CNPq pela bolsa de estudo de doutorado.

\section{REFERENCIAS}

Aksu A.E., Rubin J.P., Dudas J.R. \& Marra K.G. 2008. Role of gender and anatomical region on induction of osteogenic differentiation of human adipose-derived stem cells. Ann. Plast. Surg. 60:306-322.

Boeloni J.N., Ocarino N.M., Melo A.B., Silva J.F., Castanheira P., Goes A.M. \& Serakides R. 2009. Dose-dependent effects of triiodothyronine on osteogenic differentiation of rat bone marrow mesenchymal stem cells. Horm. Res. 72:88-97.

Boeloni J.N., Ocarino N.M., Silva J.F., Côrrea C.R., Bertollo C.M., Hell R.C., Pereira M.M., Goes A.M. \& Serakides R. 2013. Osteogenic differentiation of bone marrow mesenchymal stem cells of ovariectomized and non-ovariectomized female rats with thyroid dysfunction. Pathol. Res. Pract. 209:44-51.

Bruedigam C., Driel M.V., Koedam M., Peppel J.V., Van Der Eerden B.C., Eijken m. \& Van Leeuwen J.P. 2011. Basic techniques in human mesenchymal stem cell cultures: differentiation into osteogenic and adipogenic lineages, genetic perturbations, and phenotypic analyses. Curr. Protoc. Stem Cell Biol. 17:1-19.

Chung D., Hayashi K., Toupadakis C.A., Wong A. \& Yellowley C.E. 2012. Osteogenic proliferation and differentiation of canine bone marrow and adipose tissue derived mesenchymal stromal cells and the influence of hypoxia. Res. Vet. Sci. 91:66-75.

Datta H.K., Ng W.F., Walker J.A., Tuck S.P. \& Varanasi S.S. 2008. The cell biology of bone metabolism. J. Clin. Pathol. 61:577-587.

Dmitrieva R., Minullina I.R., Bilibina A.A., Tarasova O.V., Anisimov S.V. \& Zaritskey A.Y. 2012. Bone marrow-and subcutaneous adipose tissue-derived mesenchymal stem cells. Cell Cycle 11:377-383.

Dominici M.L., Le Blanc K., Mueller I., Slaper-Cortenbach I., Marini F., Krause D., Deans R., Keating A., Prockop D.J. \& Horwitz E. 2006. Minimal criteria for defining multipotencial mesenquimal stromal cells. The international society for cellular therapy position statement. Cytotherapy 8:315-317.

Eslaminejad W.B. \& Taghiyar L. 2010. Study of the structure os canine mesenchymal stem cell osteogenic culture. Anat. Histol. Embryol. 39:446455.

Fabian M.R., Sonenberg N. \& Filipowicz W. 2010. Regulation of mRNA translation and stability by microRNAs. Annu. Rev. Biochem. 79:351-379.

Franceschi R.T., Ge C., Xiao G., Roca H. \& Jiang D. 2009. Transcriptional regulation of osteoblasts. Cells Tissues Organs 189:144-152.
Hell R.C., Ocarino N.M., Boeloni J.N., Silva J.F., Goes A.M., Santos R.L. \& Serakides R. 2012. Physical activity improves age-related decline in the osteogenic potential of rats' bone marrow-derived mesenchymal stem cells. Acta Physiol., Oxford, 205:292-301.

Kang B.-J., Ryu H.-H., Park S.S., Yoshihisa K., Kikuchi M., Woo H.-M., Kim W.H. \& Kweon O.-K. 2012. Comparing the osteogenic potential of canine mesenchymal stem cells derived from adipose tissues, bone marrow, umbilical cord blood, and Wharton's jelly for treating bone defects. J. Vet. Sci. 13:299-310.

Kassem M., Abdallah B.M. \& Saeed H. 2008. Osteoblastic cells: differentiation and trans-differentiation. Arch. Biochem. Biophys. 473:183-187.

Lee W.S., Suzuki Y., Graves S.S., Iwata M., Venkataraman G.M., Mielcarek M., Peterson L.J., Ikehara S., Torok-Storb B. \& Storb R. 2011. Canine bone marrow-derived mesenchymal stromal cells suppress alloreactive lymphocyte proliferation in vitro but fail to enhance engraftment in canine bone marrow transplantation. Biol. Blood Marrow Transplant. 4:465475.

Levi B., Nelson E.R., Brown K., James A.W., Xu D., Dunlevier R., Wu J.C., Lee M., Wu B., Commons G.W., Vistnes D. \& Longaker M.T. 2011 . Differences in osteogenic differentiation of adipose-derived stromal cells from murine, canine, and human sources in vitro and in vivo. Plast. Reconstr. Surg. 128:373-386.

Li H.W. \& Sun J.Y. 2011. Effects of dicalcium silicate coating ionic dissolution products on human mesenchymal stem-cell proliferation and osteogenic differentiation. J. Int. Med. Res. 39:112-128.

Lin L., She Q., Wei X., Hou Y., Xue T., Fu X., Duan X. \& Yu C. 2009. Comparison of osteogenic potentials of BMP2 transduced stem cells from autologous bone marrow and fat tissue in rabbit model of calvarial defects. Calcif. Tissue Int. 85:55-65.

Martinello T., Bronzini I., Maccatrozzo L., Mollo A., Sampaolesi M., Mascarello F., Decaminada M. \& Patruno M. 2011. Canine adipose-derived mesenchymal stem cells do not lose stem features after a long-term cryopreservation. Res. Vet. Sci. 91:18-24.

Monaco E., Bionaz M., Rodrigues-Zas S., Hurley W.L. \& Wheeler M.B. 2012. Transcriptomics comparison between porcine adipose and bone marrow mesenchymal stem cells during in vitro osteogenic and adipogenic differentiation. Plos One 7:1-19.

Nakashima K., Zhou X., Kunkel G., Zhang Z., Deng J.M., Behringer R.R. \& De Crombrugghe B. 2002. The novel zinc finger-containing transcription factor osterix is required for osteoblast differentiations and bone formation. Cell 108:17-29.

Neupane M., Chang C.C., Kiupel M. \& Yuzbasiyan-Gurkan V. 2008. Isolation and characterization of canine adipose-derived mesenquimal stem cells. Tissue Eng. A 14:1007-1015.

Ocarino N.M., Boeloni J.N., Goes A.M., Silva J.F., Marubayashi U. \& Serakides R. 2008. Osteogenic differentiation of mesenchymal stem cells from osteopenic rats subjected to physical activity with and without nitric oxide synthase inhibition. Nitric Oxide 19:320-325.

Park S.H., Sim W.Y., Min B.H., Yang S.S., Khademhosseini A. \& Kaplan D.L. 2012. Chip-based comparison of the osteogenesis of human bone marrow-and adipose tissue-derived mesenchymal stem cells under mechanical stimulation. Plos One 7:1-11.

Payushina O.V., Domaratskaya E.I. \& Starostin V.I. 2006. Mesenchymal stem cells: sources, phenotype, and differentiation potential. Cell Biol. 33:2-18.

Prophet E.B., Mills B., Arrington J.B. \& Sobin L.H. 1992. AFIP Laboratory Methods in Histotechnology. Armed Forces Institute of Pathology, Washington, DC. 278p.

Ranera B., Ordovas L., Lyahyai J., Bernal M.L., Fernandes F., Remacha A.R., Romero A., Vazquez F.J., Osta R., Cons C., Varona L., Zaragoza P., Martín-Burriel L. \& Rodellar C. 2012. Comparative study of equine bone marrow and adipose tissue-derived mesenchymal stromal cells. Equine Vet. J. 44:33-42.

Rozemuller H., Prins H., Naaijkens B., Staal J., Buhring H.J. \& Martens A.C. 2010. Prospective isolation of mesenquimal stem cells from multiples mammalian species using cross-reaction anti human monoclonal antibodies. Stem Cells Dev. 19:1911-1921. 
Sampaio I.B.M. 1998. Estatística Aplicada à Experimentação Animal. FEP/ MVZ, Belo Horizonte. 211p.

Seo M.S., Jeong Y.H., Park J.R., Park S.B., Rho K.H., Kim H.S., Yu K.R., Lee S.H., Jung J.W., Lee Y.S. \& Kang K.S. 2009. Isolation and characterization of canine umbilical cord blood-derived mesenchymal stem cells. J. Vet. Sci. 10:181-187.

Spencer N.D., Chun R., Vidal M.A., Gimble J.M. \& Lopez M.J. 2012. In vitro expansion and differentiation of fresh and revitalized adult canine bone marrow-derived and adipose tissue-derived stromal cells. Vet. J. 191:231-239.
Strioga M., Viswanathan S., Darinskas A., Slaby O. \& Michalek J. 2012. Same or not the same? Comparison of adipose tissue-derived versus bone marrow-derived mesenchymal stem and stromal cells. Stem Cells Dev. 21:2724-2752.

Takemitsu H., Zhao D., Yamamoto I., Harada Y., Michishita M. \& and Arai T. 2012. Comparison of bone marrow and adipose tissue-derived canine mesenchymal stem cells. BMC Vet. Res. 8:1-9.

Vieira N.M., Brandalise V., Zucconi E., Secco M., Strauss B.E. \& Zatz M. 2010. Isolation, characterization, and differentiation potential of canine adipose-derived stem cells. Cell Transplant. 19:279-289. 